\title{
Photolysis of Fluorinated Graphites with Embedded Acetonitrile Using a White-Beam Synchrotron Radiation
}

\author{
Galina I. Semushkina ${ }^{1}, *$, Yuliya V. Fedoseeva ${ }^{1}\left(\mathbb{D}\right.$, Anna A. Makarova ${ }^{2}$, Dmitry A. Smirnov ${ }^{3}$, Igor P. Asanov ${ }^{1}{ }^{1}$, \\ Dmitry V. Pinakov ${ }^{1}\left(\mathbb{D}\right.$, Galina N. Chekhova $^{1}$, Alexander V. Okotrub ${ }^{1}$ (I) and Lyubov G. Bulusheva ${ }^{1, *(1)}$
}

1 Nikolaev Institute of Inorganic Chemistry SB RAS, 3, Acad. Lavrentiev Ave., 630090 Novosibirsk, Russia; fedoseeva@niic.nsc.ru (Y.V.F.); asan@niic.nsc.ru (I.P.A.); pinakov@niic.nsc.ru (D.V.P.); chekhova@niic.nsc.ru (G.N.C.); spectrum@niic.nsc.ru (A.V.O.)

2 Physikalische Chemie, Institut für Chemie und Biochemie, Freie Universität Berlin, 14195 Berlin, Germany; anna.makarova@fu-berlin.de

3 Institut für Festkörper- und Materialphysik, Technische Universität Dresden, 01069 Dresden, Germany; dmitry.smirnov@helmholtz-berlin.de

* Correspondence: semushkina.g@niic.nsc.ru (G.I.S.); bul@niic.nsc.ru (L.G.B.)

Citation: Semushkina, G.I.; Fedoseeva, Y.V.; Makarova, A.A.; Smirnov, D.A.; Asanov, I.P.; Pinakov, D.V.; Chekhova, G.N.; Okotrub, A.V.; Bulusheva, L.G. Photolysis of Fluorinated Graphites with Embedded Acetonitrile Using a White-Beam Synchrotron Radiation. Nanomaterials 2022, 12, 231. https:// doi.org/10.3390/nano12020231

Academic Editor: Werner Blau

Received: 30 November 2021

Accepted: 5 January 2022

Published: 11 January 2022

Publisher's Note: MDPI stays neutral with regard to jurisdictional claims in published maps and institutional affiliations.

Copyright: (c) 2022 by the authors. Licensee MDPI, Basel, Switzerland. This article is an open access article distributed under the terms and conditions of the Creative Commons Attribution (CC BY) license (https:// creativecommons.org/licenses/by/ $4.0 /)$.

\begin{abstract}
Fluorinated graphitic layers with good mechanical and chemical stability, polar C-F bonds, and tunable bandgap are attractive for a variety of applications. In this work, we investigated the photolysis of fluorinated graphites with interlayer embedded acetonitrile, which is the simplest representative of the acetonitrile-containing photosensitizing family. The samples were continuously illuminated in situ with high-brightness non-monochromatized synchrotron radiation. Changes in the compositions of the samples were monitored using X-ray photoelectron spectroscopy and near-edge X-ray absorption fine structure (NEXAFS) spectroscopy. The NEXAFS N K-edge spectra showed that acetonitrile dissociates to form $\mathrm{HCN}$ and $\mathrm{N}_{2}$ molecules after exposure to the white beam for $2 \mathrm{~s}$, and the latter molecules completely disappear after exposure for $200 \mathrm{~s}$. The original composition of fluorinated matrices $\mathrm{CF}_{0.3}$ and $\mathrm{CF}_{0.5}$ is changed to $\mathrm{CF}_{0.10}$ and $\mathrm{GF}_{0.17}$, respectively. The highly fluorinated layers lose fluorine atoms together with carbon neighbors, creating atomic vacancies. The edges of vacancies are terminated with the nitrogen atoms and form pyridinic and pyrrolic units. Our in situ studies show that the photolysis products of acetonitrile depend on the photon irradiation duration and composition of the initial $\mathrm{CF}_{\mathrm{x}}$ matrix. The obtained results evaluate the radiation damage of the acetonitrile-intercalated fluorinated graphites and the opportunities to synthesize nitrogen-doped graphene materials.
\end{abstract}

Keywords: fluorinated graphite; acetonitrile; non-monochromatized synchrotron radiation; photolysis; XPS; NEXAFS

\section{Introduction}

Fluorinated graphites are layered carbon materials possessing a good chemical, mechanical, and thermal stability [1,2]. Fluorination of graphite using inorganic fluorides at room temperature produces compounds with a composition $\mathrm{CF}_{\mathrm{x}}$, where $\mathrm{x}$ is usually below $0.5[3,4]$. The molecules from the reaction media fill the space between the fluorinated layers and they can be replaced by other inorganic or organic guests [5]. Since such compounds are stable at ambient conditions for a long time, the fluorinated graphites are considered as containers for the storage and transport of volatile and hazardous substances [6].

The distance between fluorinated layers varies from $\sim 0.6$ to $\sim 1.5 \mathrm{~nm}$ depending on the size and packing of the guest molecules [7]. A very weak (if any) interaction between the layers causes a two-dimensional (2D) magnetic behavior of these materials [8]. Their exfoliation in appropriate solvents allows producing thin films of the fluorinated graphene layers [9], which are promising materials for gas sensors and energy applications $[9,10]$. Guest molecules affect the thermal stability of the fluorinated graphite compounds [5] and 
the structure of the exfoliated graphene-like materials, particularly, their specific surface area [11] and functional composition [12].

Fluorinated graphites $\mathrm{CF}_{\mathrm{x}}$ have a bandgap of about $2.5-3.0 \mathrm{eV}$, when $\mathrm{x}$ is between 0.4 and $0.5[13,14]$. They are transparent for visible light, however, the optical properties depend on the guest nature [15]. Due to a large energy gap, fluorinated graphites possess photoluminescence $[16,17]$ and may have a perspective as optical elements, sensors, and for photo-chemotherapy. To clarify the feasibility of these applications, the photostability of the compounds should be studied.

The interlayer space of fluorinated graphite $\mathrm{CF}_{\mathrm{x}}(\mathrm{x} \leq 0.5)$ is easily occupied by acetonitrile $[18,19]$. This molecule contains an element (nitrogen) that is absent in $\mathrm{CF}_{\mathrm{x}}$ and therefore is a convenient probe for studying host-guest interactions under illumination. Photolysis of acetonitrile attracts attention because these molecules are present in interstellar medium [20] and understanding of the acetonitrile fragmentation by ionizing radiation can shed light on the early stages of stars formation [21]. A study of the photolysis of gaseous acetonitrile using synchrotron radiation (SR) in the 7-22 eV range revealed the formation of $\mathrm{CN}$ and $\mathrm{CH}$ species [22]. An increase of the photon energy to $42 \mathrm{eV}$ allowed for additional registration of the signals from $\mathrm{C}_{2} \mathrm{H}_{2}{ }^{+}, \mathrm{C}_{2} \mathrm{~N}^{+}$ions and a weak signal from $\mathrm{N}^{2+}$ [20]. The ultraviolet (UV) irradiation of an $\mathrm{H}_{2} \mathrm{O}: \mathrm{CH}_{3} \mathrm{CN}$ ice at $20 \mathrm{~K}$ yielded a large number of nitriles [23]. Experiments show that the mechanism of photolysis of acetonitrile depends on the energy and power of the exciting radiation as well as its chemical environment. A fluorinated graphite matrix may also affect the photo-induced decomposition of the guest molecules.

The radiation of synchrotron light sources covers a wide range of photon energies, and the photon beam is characterized by high intensity and small focus size. Changes in the composition and electronic state of a compound after exposure to SR can be immediately recorded using X-ray photoelectron spectroscopy (XPS) and near-edge X-ray fine structure (NEXAFS) spectroscopy. The use of tunable SR makes it possible to excite certain electron transitions and study the fragmentation of a compound depending on these states [24]. Non-monochromatized SR light includes a wide range of wavelengths from infrared to hard X-rays with very high intensities. The effect of this polychromatic light on a material determines the material's resistance to wide-range irradiation, which is important for assessing its possible radiation damage. Illumination with non-monochromatized SR light is also effective for the synthesis of various nanomaterials, for example, gold nanoparticles [25] and the metastable form of carbon, carbyne [26]. It has been shown that this method is useful for tuning the functional composition of carbon nanotubes [27] and graphene materials [28].

This work is aimed at an in situ XPS and NEXAFS study of fluorinated graphites with embedded acetonitrile molecules after continuous illumination with a high-intensity polychromatic photon beam (zero-order light from the dipole beamline of the BESSY II synchrotron radiation facility). We investigated two samples differing in the content of fluorine and acetonitrile. Density functional theory (DFT) calculations of a fluorinated graphene fragment are used to interpret experimental data.

\section{Materials and Methods}

\subsection{Materials}

Purified natural graphite (the Zavalevskoe deposit, Ukraine) was used as a starting material. The typical size of graphite crystallites was $0.4 \times 0.3 \times 0.02 \mathrm{~mm}$. First, graphite was activated in saturated $\mathrm{Br}_{2}$ vapor for 2 days and then the weighed samples were located in Teflon reactors over a liquid mixture of $\mathrm{Br}_{2}$ and $\mathrm{BrF}_{3}$. The reactors were hermetically closed and kept at room temperature. The synthesis products were washed with $\mathrm{Br}_{2}$ to remove residual $\mathrm{BrF}_{3}$ and then many times with acetonitrile. The acetonitrile treatment was completed when the washout became colorless, which meant that $\mathrm{Br}_{2}$ was removed from the fluorinated graphite interlayer space and replaced with $\mathrm{CH}_{3} \mathrm{CN}$. Finally, the samples were dried in a $\mathrm{N}_{2}$ flow to their constant weights. 
The content of carbon, fluorine, bromine, and nitrogen in the samples was determined from the analysis of products of high-temperature destruction of samples in an oxygen atmosphere [19]. According to the obtained data, the composition of the yellow sample (49 days with $13.89 \mathrm{wt} \% \mathrm{BrF}_{3}$ in $\mathrm{Br}_{2}$ ) can be represented as $\mathrm{CF}_{0.5} \mathrm{Br}_{0.005} 0.070 \mathrm{CH}_{3} \mathrm{CN}$ and the green-brown sample (87 days with $5.04 \mathrm{wt} \% \mathrm{BrF}_{3}$ in $\mathrm{Br}_{2}$ ) as $\mathrm{CF}_{0.3} \mathrm{Br}_{0.005} 0.054 \mathrm{CH}_{3} \mathrm{CN}$. Bromine found in these compounds forms covalent bonds with carbon edges of graphite domains. Below, the studied samples will be denoted $\mathrm{CH}_{3} \mathrm{CN} @ \mathrm{CF}_{0.5}$ and $\mathrm{CH}_{3} \mathrm{CN} @ \mathrm{CF}_{0.3}$.

\subsection{Measurements}

XPS spectra of initial samples were measured on a Specs PHOIBOS 150 spectrometer (Specs $\mathrm{GmbH}$, Berlin, Germany) using an $\mathrm{Al} \mathrm{K} \mathrm{K}_{\alpha}$ excitation radiation (1486.7 eV). The spot size of the photon beam was about $3 \mathrm{~mm}$. The Casa XPS 2.3.15 software (Casa Software Ltd., Teignmouth, UK) was used for data processing. The C 1s, F 1s, and N 1s spectra were fitted by a product of Gaussian-Lorentzian (7:3) peaks after subtraction of a Shirley background. The binding energies were calibrated to the $\mathrm{C}\left(\mathrm{sp}^{2}\right)$ component energy at $284.5 \mathrm{eV}$.

Irradiations of samples by non-monochromatized SR light (white beam) and subsequent XPS and NEXAFS experiments were carried out at the Russian-German dipole beamline (RGBL Dipole, BESSY II, Berlin, Germany) operated by Helmholtz-Zentrum Berlin für Materialien und Energie. The total light intensity can be estimated as $50 \mathrm{~mJ} / \mathrm{cm}^{2}$ [27]. The samples are non-conducting; therefore, they were deposited on copper substrates with a scratched surface (roughness $\sim 100 \mu \mathrm{m}$ ) in the thinnest possible layers. The substrates were fixed on a holder and placed in a vacuum chamber providing a residual pressure of $10^{-10}$ mbar. After acquiring the NEXAFS spectra in total electron yield (TEY) mode, the samples were exposed to a non-monochromatized photon beam for a certain period, and XPS and NEXAFS spectra were recorded directly for the irradiated spots $(\sim 1 \times 1 \mathrm{~mm})$. The measurements of the spectra accompanied each step of the sample irradiations. The irradiation experiments were repeated at different spots of the samples, and they showed the same trend in the spectral modifications depending on the exposure time. XPS spectra were excited by a photon energy of $830 \mathrm{eV}$. The binding energies were aligned to the position of the $\mathrm{Au} 4 \mathrm{f}_{7 / 2}$ line at $84 \mathrm{eV}$ recorded from a clean $\mathrm{Au}$ foil. Mass-spectra were registered upon an irradiation of $\mathrm{CH}_{3} \mathrm{CN} @ \mathrm{CF}_{0.3}$ in a scan mode for $m / z$ ( $\sim 30$ scans during $\left.4 \mathrm{~s}\right)$. The residual gas analyzer Extorr XT100M (Extorr Inc., New Kensington, PA, USA) was operated with an electron impact ionizer with an energy of $70 \mathrm{eV}$.

\subsection{Calculations}

DFT calculations were carried out using the three-parameter hybrid Becke and LeeYang-Parr exchange-correlation functional (B3LYP) [29,30] implemented in the program package Jaguar (Jaguar, version 10.3, Schrödinger, Inc., New York, NY, USA, 2019). Atomic orbitals were described by the $6-31 \mathrm{G}^{*}$ basis set.

A graphene fragment of a $\mathrm{C}_{96}$ composition and $\mathrm{D}_{6 \mathrm{~h}}$ symmetry was taken to construct the fluorinated models. Saturation of dangling bond of an edge carbon atom by one fluorine atom yielded the $\mathrm{C}_{96} \mathrm{~F}_{24}$ model. An attachment of fluorine atoms to both sides of the basal graphene plane, like in fluorographene [31], and bonding of an edge carbon atom with two fluorine atoms produced the $\mathrm{C}_{96} \mathrm{~F}_{120}$ model. The geometries of the models were optimized by an analytic gradient method to default convergence criteria. Then, we removed 34 central fluorine atoms from the $\mathrm{C}_{96} \mathrm{~F}_{120}$ fragment to form aromatic and polyene carbon areas in partially fluorinated graphene according to that observed experimentally [32]. The obtained partially fluorinated $\mathrm{C}_{96} \mathrm{~F}_{86}$ model was optimized at fixed positions of the boundary atoms.

Theoretical NEXAFS C K- and F K-edge spectra were plotted using the results of DFT calculations of the fluorinated models, where a carbon atom or a fluorine atom was replaced by an atom of nitrogen or neon, respectively. This so-called $(Z+1)$ approximation accounts for the effect of the core level hole on spectral profile [33]. To compensate for an increase in the number of valence electrons, the system charge was +1 . The $(Z+1)$ approximation was used for the selected carbon or fluorine atoms located in structurally 
non-equivalent positions. The geometries of the structures with a neon were not optimized to avoid detachment of the neon atom. Spectral intensities were calculated as the sum of the squares of the coefficients, with which the atomic orbitals of nitrogen or neon participate in the formation of unoccupied molecular orbitals (MOs). The calculated intensities were broadened by Lorentz functions with a variable width of $1.4-4.0 \mathrm{eV}$, increasing with the photon energy, the spectral background was described by an arctan function [34]. X-ray transition energies were determined as the difference between the Kohn-Sham energies of the virtual MOs of the models calculated within the $(Z+1)$ approximation and energy of the core levels of the selected carbon or fluorine atoms, taken from the calculation of the ground state of the fluorinated model. The spectrum for a central nitrogen atom in the $\mathrm{C}_{96} \mathrm{~F}_{24}$ model calculated within the $(Z+1)$-approximation (Figure S1, Supporting Information) was aligned to the experimental C K-edge spectrum of graphite by the position of $\pi^{*}$ and $\sigma^{*}$ peaks. The obtained scaling formula was used to calibrate the energy of other theoretical $\mathrm{C}$ K-edge spectra. The calibration of energy for theoretical F K-edge spectra was done from the comparison of the calculated spectrum for the $\mathrm{C}_{96} \mathrm{~F}_{120}$ model and the experimental spectrum of fully fluorinated graphite $(\mathrm{CF})_{\mathrm{n}}$ (Figure S1, Supporting Information).

\section{Results}

\subsection{XPS C 1s and F 1s Spectra}

XPS measurements were used to evaluate the changes in the composition of $\mathrm{CH}_{3} \mathrm{CN} @ \mathrm{CF}_{0.3}$ and $\mathrm{CH}_{3} \mathrm{CN} @ \mathrm{CF}_{0.5}$ samples before and after illumination with high-brilliance non-monochromatized SR light. The content of the elements was determined from the survey spectra (not shown) taking into account atomic subshell photoionization crosssections of elements at a given excitation energy. Atomic concentrations of main elements are collected in Table 1. The content of fluorine and nitrogen in the two studied samples differs by a factor of two in line with the data of elemental analysis. The XPS-derived $\mathrm{F} / \mathrm{C}$ ratio is 0.16 for $\mathrm{CH}_{3} \mathrm{CN} @ \mathrm{CF}_{0.3}$ and 0.37 for $\mathrm{CH}_{3} \mathrm{CN}_{\mathrm{N}} \mathrm{CF}_{0.5}$. Since XPS is a surfacesensitive method, it detects the low content of fluorine in the upper surface layers of the samples as a result of their partial de-fluorination due to the contact with $\mathrm{H}_{2} \mathrm{O}$ present in laboratory atmosphere [35]. Higher oxygen content on the surface of $\mathrm{CH}_{3} \mathrm{CN} @ \mathrm{CF}_{0.3}$ than for $\mathrm{CH}_{3} \mathrm{CN} @ \mathrm{CF}_{0.5}$ may indicate an easier replacement of fluorine by oxygen in this sample. The weakness of $\mathrm{C}-\mathrm{F}$ bonds in $\mathrm{CH}_{3} \mathrm{CN} @ \mathrm{CF}_{0.3}$ results in almost complete removal of surface fluorine under the photon irradiation. While the $\mathrm{CH}_{3} \mathrm{CN} @ \mathrm{CF}_{0.5}$ sample keeps about 3 at\% of fluorine even after 200-s exposure to polychromatic synchrotron light. XPS also detects nitrogen from $\mathrm{CH}_{3} \mathrm{CN}$ molecules in both initial samples and after each step of the irradiation.

Table 1. XPS determined content (at\%) of main elements in $\mathrm{CH}_{3} \mathrm{CN} @ \mathrm{CF}_{0.3}$ and $\mathrm{CH}_{3} \mathrm{CN} @ \mathrm{CF}_{0.5}$ samples before and after exposure to polychromatic synchrotron light for 80 and $200 \mathrm{~s}$. The ratio of the areas of the $\mathrm{C}-\mathrm{CF}$ to $\mathrm{C}-\mathrm{F}$ components in the XPS C 1s spectra (last column).

\begin{tabular}{cccccc}
\hline Exposure Time, $\mathbf{s}$ & $\mathbf{C}$ & $\mathbf{F}$ & $\mathbf{N}$ & $\mathbf{O}$ & $\mathbf{C}-\mathbf{C F} / \mathbf{C}-\mathbf{F}$ \\
\hline \multicolumn{7}{c}{$\mathrm{CH}_{3} \mathrm{CN}_{\mathrm{C}} \mathrm{CF}_{0.3}$} \\
0 & 83 & 13 & 1 & 3 & \\
80 & 98 & $<1$ & $<1$ & $<1$ & 1.9 \\
200 & 98 & $<1$ & $<1$ & $<1$ & 1.9 \\
\multicolumn{7}{c}{$\mathrm{CH}_{3} \mathrm{CN}_{0} \mathrm{CF}_{0.5}$} & & \\
0 & 71 & 26 & 2 & 1 & 1.0 \\
80 & 90 & 6 & 3 & 1 & 2.0 \\
200 & 95 & 3 & 2 & $<1$ & 2.2 \\
\hline
\end{tabular}

Figure 1 compares XPS C 1s and F 1s spectra of the samples. C 1s spectra of initial $\mathrm{CH}_{3} \mathrm{CN} @ \mathrm{CF}_{0.5}$ and $\mathrm{CH}_{3} \mathrm{CN} @ \mathrm{CF}_{0.3}$ are fitted by four components (Figure 1a,b). The binding energies and the relative areas of the components are listed in Table S1. A weak component at $\sim 287 \mathrm{eV}$ corresponds to carbon in guest acetonitrile molecules [36]. The low-energy 
component at $284.5 \mathrm{eV}$ originates from $\mathrm{sp}^{2}$-carbon areas remaining in the fluorinated layers and its intensity is higher for the $\mathrm{CF}_{0.3}$ matrix than for $\mathrm{CF}_{0.5}$. The peaks at 288.7 and $286.1 \mathrm{eV}$ in the $\mathrm{CH}_{3} \mathrm{CN} @ \mathrm{CF}_{0.5}$ spectrum characterize carbon atoms covalently bonded to fluorine (C-F) and located at CF groups (C-CF), respectively [37]. These peaks are downshifted by $0.7 \mathrm{eV}$ for $\mathrm{CH}_{3} \mathrm{CN} @ \mathrm{CF}_{0.3}$ due to the weakening of $\mathrm{C}-\mathrm{F}$ bonds [38,39]. The intensity of the C-F peak correlates with fluorine content in the samples (Table 1). The ratio of the C-F component to the total area of the $\mathrm{C} 1$ s spectrum gives matrix stoichiometry $\mathrm{CF}_{0.24}$ for the $\mathrm{CH}_{3} \mathrm{CN} @ \mathrm{CF}_{0.3}$ sample and $\mathrm{CF}_{0.43}$ for the $\mathrm{CH}_{3} \mathrm{CN} @ \mathrm{CF}_{0.5}$ sample. The $\mathrm{C}-\mathrm{CF} / \mathrm{C}-\mathrm{F}$ ratio gives the average number of bare carbon atoms near $\mathrm{CF}$ groups. The ratio 1 for $\mathrm{CH}_{3} \mathrm{CN} @ \mathrm{CF}_{0.5}$ (Table 1) indicates an average of one bare carbon neighbor for a CF group. Such a ratio can be realized when CF chains alternate with bare carbon chains [40,41]. An increase in the ratio value for $\mathrm{CH}_{3} \mathrm{CN} @ \mathrm{CF}_{0.3}$ is associated with the shortening of $\mathrm{CF}$ chains and increase in numbers of two bare carbon neighbors for CF groups located at the edges of short CF chains.

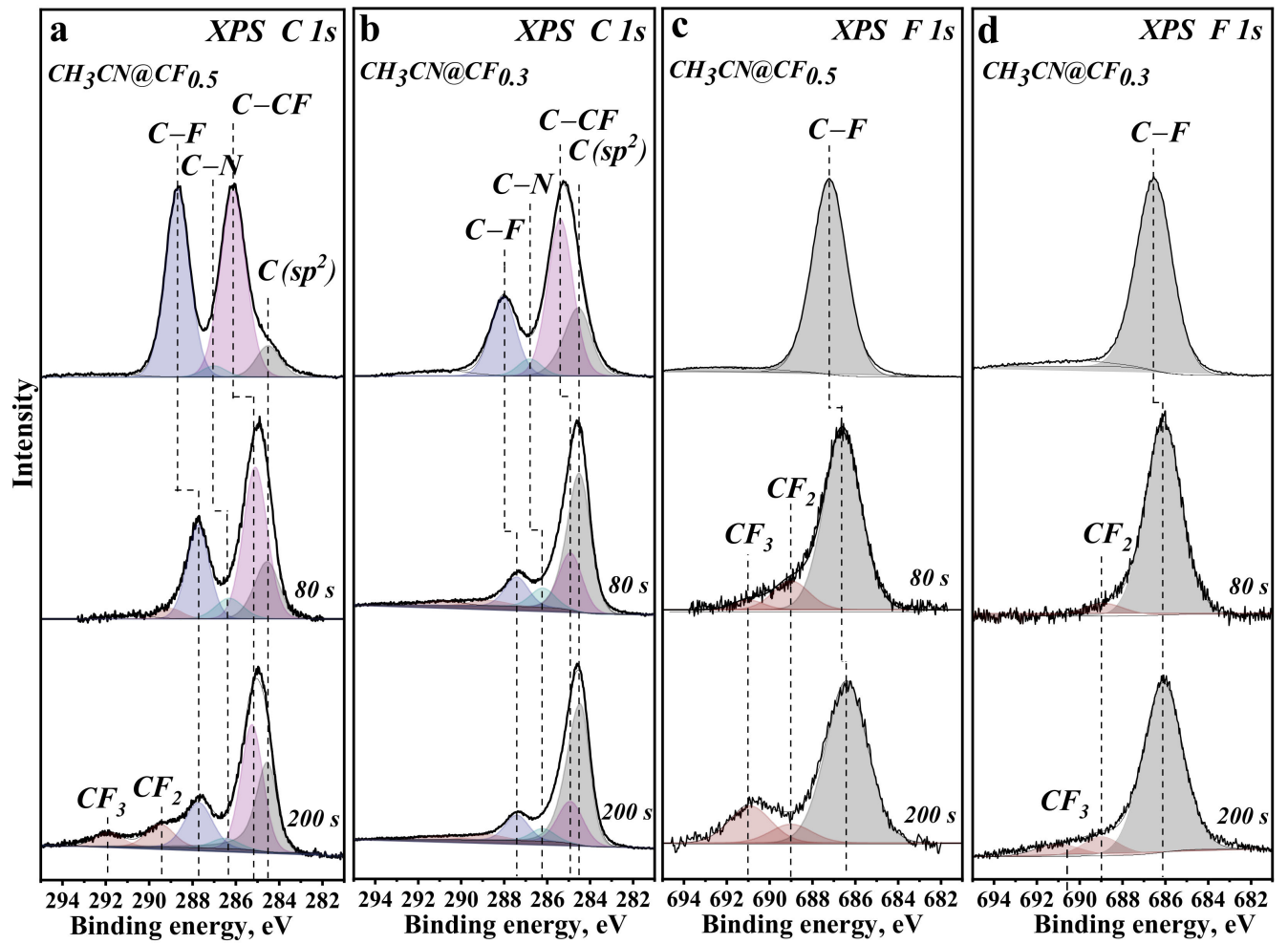

Figure 1. XPS C 1s spectra $(\mathbf{a}, \mathbf{b})$ and $\mathrm{F} 1 \mathrm{~s}$ spectra $(\mathbf{c}, \mathbf{d})$ of $\mathrm{CH}_{3} \mathrm{CN}_{\mathrm{C}} \mathrm{CF}_{0.5}(\mathbf{a}, \mathbf{c})$ and $\mathrm{CH}_{3} \mathrm{CN} @ \mathrm{CF}_{0.3}(\mathbf{b}, \mathbf{d})$ before and after white beam irradiation for $80 \mathrm{~s}$ and $200 \mathrm{~s}$.

The relative intensity of the $\mathrm{C}-\mathrm{F}$ component decreases in the $\mathrm{C}$ 1s spectra of irradiated samples (Figure $1 \mathrm{a}, \mathrm{b}$ ) due to the removal of fluorine. The shift of the C-F and C-CF components to lower binding energies indicates the weakening of $\mathrm{C}-\mathrm{F}$ bonds as compared to those in the initial samples. New components located at $\sim 289.5$ and $\sim 292 \mathrm{eV}$ are especially noticeable in the spectrum of $\mathrm{CH}_{3} \mathrm{CN} @ \mathrm{CF}_{0.5}$ after $200 \mathrm{~s}$ of the irradiation. They are assigned to carbon bonded with two $\left(\mathrm{CF}_{2}\right)$ and three fluorine atoms $\left(\mathrm{CF}_{3}\right)$ [42]. Thus, white beam partially destroys graphitic lattice. The detached carbon and fluorine atoms are combined with the $\mathrm{CF}_{2}$ and $\mathrm{CF}_{3}$ groups that bind to the edges of vacancies [43]. Analysis of the XPS $\mathrm{C}$ 1s spectra reveals that the composition of the $\mathrm{CH}_{3} \mathrm{CN} @ \mathrm{CF}_{0.5}$ and $\mathrm{CH}_{3} \mathrm{CN} @ \mathrm{CF}_{0.3}$ samples irradiated for $200 \mathrm{~s}$ is $\mathrm{CF}_{0.18}$ and $\mathrm{CF}_{0.10}$, respectively.

XPS F 1s spectra of initial $\mathrm{CH}_{3} \mathrm{CN} @ \mathrm{CF}_{0.5}$ and $\mathrm{CH}_{3} \mathrm{CN}_{\mathrm{N}} @ \mathrm{CF}_{0.3}$ exhibit a single peak at 687.2 and $686.6 \mathrm{eV}$, respectively (Figure $1 \mathrm{c}, \mathrm{d}$ ). These binding energies correspond to fluorine covalently bonded with carbon $[15,44]$. The exposure of the samples to the nonmonochromatized light leads to the emergence of fluorine states possessing higher binding 
energies. The F 1s components at 689.0 and $691.0 \mathrm{eV}$ can be attributed to fluorine in $\mathrm{CF}_{2}$ and $\mathrm{CF}_{3}$ groups [45], or the atoms located in densely fluorinated regions [44] like in $(\mathrm{CF})_{\mathrm{n}}$. However, the C-CF/C-F ratio in the XPS C 1s spectra of the samples (Table 1) indicates that most $\mathrm{CF}$ groups have one or two bare carbon atoms as their neighbors, and this differs from the fluorine arrangement in $(\mathrm{CF})_{\mathrm{n}}$. Amounts of $\mathrm{CF}_{2}$ and $\mathrm{CF}_{3}$ groups are larger in the irradiated $\mathrm{CH}_{3} \mathrm{CN} @ \mathrm{CF}_{0.5}$ than in the irradiated $\mathrm{CH}_{3} \mathrm{CN} @ \mathrm{CF}_{0.3}$.

\subsection{NEXAFS C K-Edge and F K-Edge Spectra}

NEXAFS spectra measured before and after sequential irradiation of $\mathrm{CH}_{3} \mathrm{CN} @ \mathrm{CF}_{0.5}$ and $\mathrm{CH}_{3} \mathrm{CN} @ \mathrm{CF}_{0.3}$ for 20, 80, and 200 s are presented in Figure 2. The difference in the binding energies of the XPS F 1s peak and the C-F component of the XPS C 1s spectrum (Figure 1) is used for the energy alignment of NEXAFS C K- and F K-edge spectra of the particular sample.
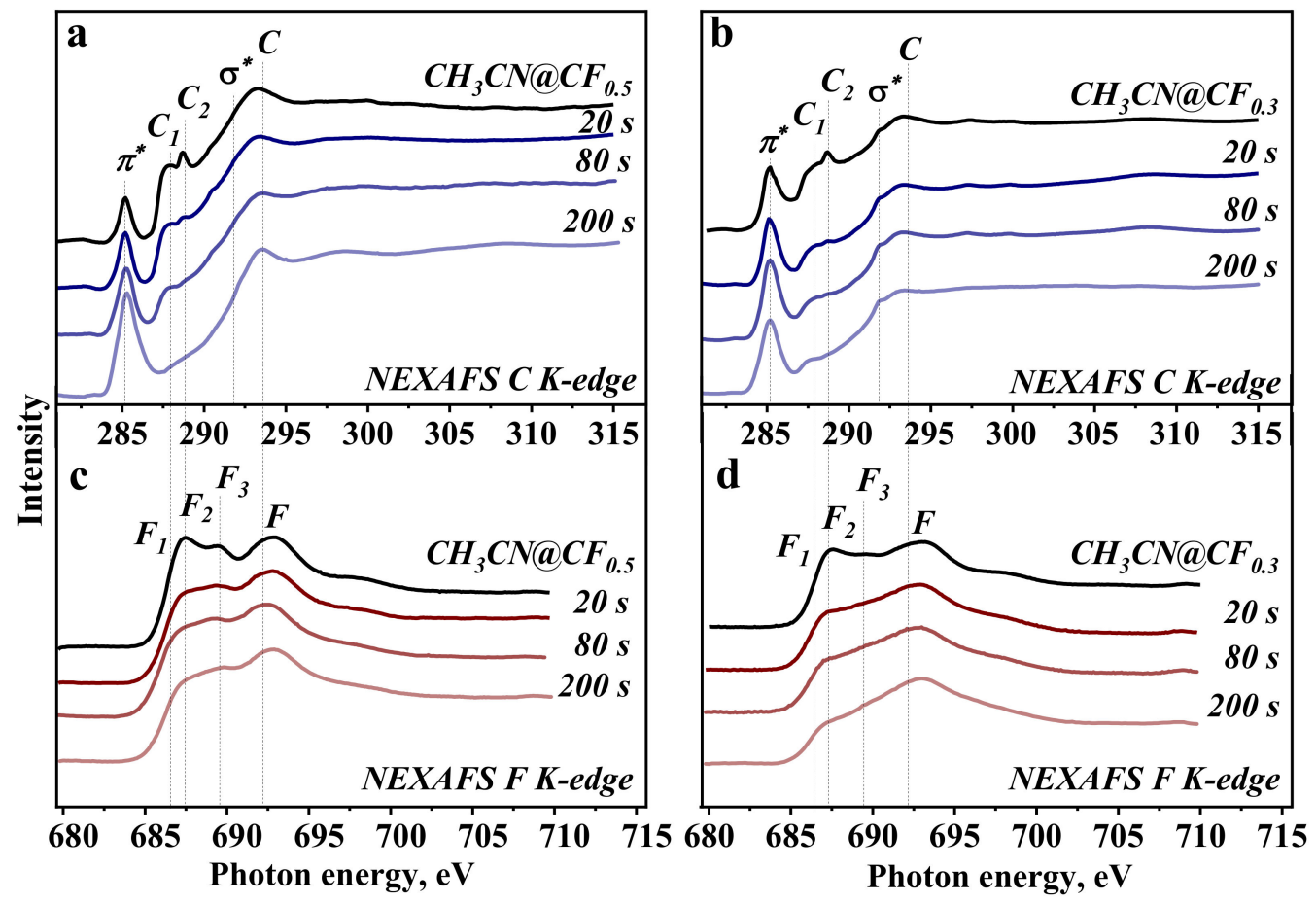

Figure 2. NEXAFS $\mathrm{C}$ K-edge $(\mathbf{a}, \mathbf{b})$ and $\mathrm{F}$ K-edge $(\mathbf{c}, \mathbf{d})$ spectra of $\mathrm{CH}_{3} \mathrm{CN} @ \mathrm{CF}_{0.5}(\mathbf{a}, \mathbf{c})$ and $\mathrm{CH}_{3} \mathrm{CN} @ \mathrm{CF}_{0.3}(\mathbf{b}, \mathbf{d})$ before (upper curves) and after irradiation by white beam for $20 \mathrm{~s}, 80 \mathrm{~s}$, and $200 \mathrm{~s}$.

NEXAFS C K-edge spectra of all samples exhibit $\pi^{*}$ and $\sigma^{*}$ resonances at 285.1 and $291.9 \mathrm{eV}$ (Figure 2a,b) assigned to the electron transitions from C 1s levels onto unoccupied $\pi$-type and $\sigma$-type states for $\mathrm{sp}^{2}$-hybridized carbon, respectively [46-48]. The peaks, which appeared between these resonances at 287.8 and $288.8 \mathrm{eV}$ and labeled $\mathrm{C}_{1}$ and $\mathrm{C}_{2}$, correspond to carbon bonded with fluorine $[49,50]$. In the spectrum of starting $\mathrm{CH}_{3} \mathrm{CN} @ \mathrm{CF}_{0.5}$, these peaks are more prominent, while the $\pi^{*}$ resonance has the lowest intensity (Figure 2a). The letter $C$ denotes the position of $\sigma^{*}$-edge for the fluorinated areas because it coincides with the last intense peak (labeled F) of the F K-edge spectra (Figure 2c,d). The shoulder $F_{1}$ at $686.5 \mathrm{eV}$ and the peak $F_{2}$ at $687.4 \mathrm{eV}$ align with peaks $C_{1}$ and $C_{2}$ of the $C$ K-edge spectra and therefore they refer to the $\mathrm{C}-\mathrm{F}$ bonds. The illumination of $\mathrm{CH}_{3} \mathrm{CN} @ \mathrm{CF}_{0.5}$ and $\mathrm{CH}_{3} \mathrm{CN} @ \mathrm{CF}_{0.3}$ samples with polychromatic synchrotron beam results in the suppression of $C_{1}$ and $C_{2}$ peaks in $C K$-edge spectra and $F_{1}$ and $F_{2}$ peaks in $F$ K-edge spectra and the growth of relative intensity of $\pi^{*}$ resonance from $\mathrm{sp}^{2}$-carbon. The changes are stronger with increasing exposure time and correlate with the behavior observed in the XPS C 1s spectra of the samples (Figure 1). 
To interpret NEXAFS C K-edge and F K-edge spectra in detail, NEXAFS spectra for structurally nonequivalent carbon and fluorine atoms present in the partially fluorinated graphitic monolayer are constructed (Figure 3). The spectra of the starting and irradiated for $200 \mathrm{~s} \mathrm{CH} \mathrm{CN}_{3} @ \mathrm{CF}_{0.5}$ sample are chosen for the modeling (Figure 3a,b). The calculated fluorinated graphene fragment is shown in Figure 3c. Theoretical spectra are constructed for the carbon and fluorine atoms from CF groups surrounded by three (CF-3), two (CF-2), one (CF-1), and none (CF-0) fluorinated carbon atoms. We also calculate the C K-edge spectra for bare carbon atoms from polyene-like chain (C-ch) and aromatic naphthalene-like area (C-ar).
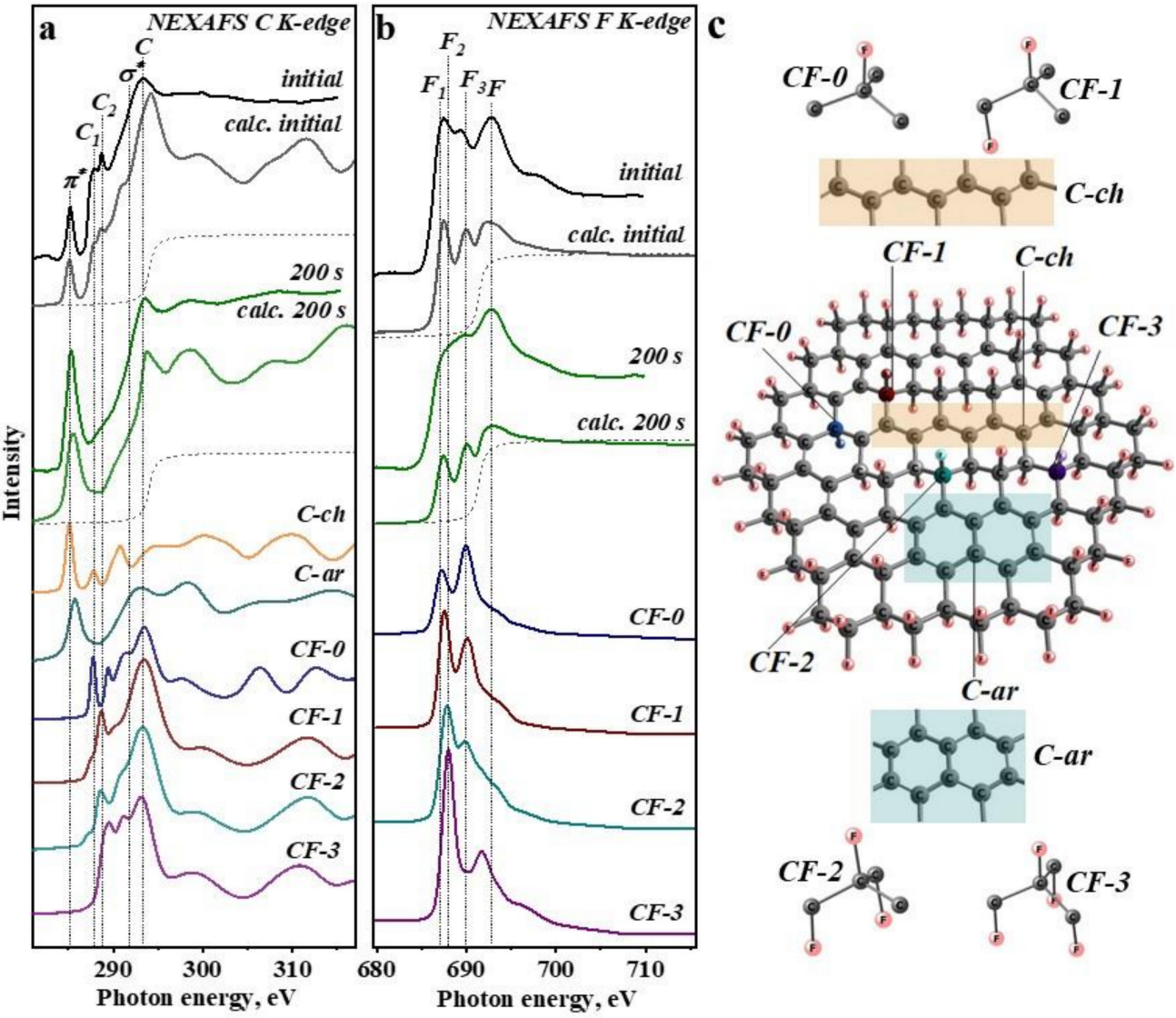

Figure 3. Experimental NEXAFS C K-edge (a) and F K-edge (b) spectra of $\mathrm{CH}_{3} \mathrm{CN} @ \mathrm{CF}_{0.5}$ before (black) and after white beam irradiation for $200 \mathrm{~s}$ (olive) in comparison with the theoretical spectra calculated for carbon (a) and fluorine (b) atoms from CF-0, CF-1, CF-2, and CF-3 groups and bare carbon atoms from polyene chain $(\mathrm{C}-\mathrm{ch})$ and aromatic area $(\mathrm{C}-\mathrm{ar})$ of the partially fluorinated graphene model (c).

Comparison of the $\mathrm{C}$ K-edge spectrum of initial $\mathrm{CH}_{3} \mathrm{CN}_{0} @ \mathrm{CF}_{0.5}$ with the calculated spectra shows that energy of $\pi^{*}$ resonance corresponds to the position of the low-energy intense peak in the spectrum of $\mathrm{C}$-ch (Figure 3a). This result indicates that most of the $\mathrm{sp}^{2}$-hybridized carbon atoms in the fluorinated $\mathrm{CF}_{0.5}$ layers form polyene-like chains, that is in agreement with the previous data $[40,51]$. Peak $C_{1}$ originates from carbon in isolated $C F$ groups (CF-0), while carbon atoms from $\mathrm{CF}-1$ and $\mathrm{CF}-2$ groups, where $\mathrm{CF}$ groups have one and two $C F$ neighbors, respectively, contribute to the peak $C_{2}$ in the experimental spectrum. Fluorine atoms from CF-1 and CF-2 groups are responsible for intense peaks $\mathrm{F}_{2}$ and $\mathrm{F}_{3}$ in the F K-edge spectrum of $\mathrm{CH}_{3} \mathrm{CN} @ \mathrm{CF}_{0.5}$ (Figure 3b). Shoulder $\mathrm{F}_{1}$ is assigned to fluorine from isolated CF-0 groups. Analysis of MOs calculated in the $(Z+1)$-approximation reveals that spectral features $F_{1}, F_{2}$, and $F_{3}$ correspond to $C-F$ bonds of $\sigma^{*}$-type (Figure S2, Supporting Information). The difference in energy is due to the different local distribution of electron 
density between this bond and the neighbors. The high-energy peak $\mathrm{F}$ is formed by an overlapping of $\mathrm{F} 2 \mathrm{p}_{\mathrm{x}, \mathrm{y}}$ orbitals with neighboring $\mathrm{C}-\mathrm{C} \sigma$-bonds.

The cumulative theoretical $\mathrm{C}$ K-edge spectrum obtained by summing the spectral intensity of carbon from C-ch, CF-0, CF-1, and CF-2 taken in a ratio of 1.8:1:1:1.8 perfectly repeats the shape of the experimental spectrum of initial $\mathrm{CH}_{3} \mathrm{CN}_{0} @ \mathrm{CF}_{0.5}$ (two upper curves in Figure 3a). The cumulative $\mathrm{F} \mathrm{K}$-edge spectrum being a sum of the theoretical spectra of fluorine from CF-0, CF-1, and CF-2 taken in a proportion of 1:1:1.8 also agrees well with the experimental spectrum of $\mathrm{CH}_{3} \mathrm{CN} @ \mathrm{CF}_{0.5}$ (two upper curves in Figure $3 \mathrm{~b}$ ). $\mathrm{CF}-3$ groups with three $\mathrm{CF}$ neighbors are not necessary to define all spectral features; probably, they are hardly formed in the synthesis conditions used. Fluorine distribution in the layers of a $\mathrm{CF}_{0.5}$ composition is mainly realized as $\mathrm{CF}$ chains separated by polyene-like carbon chains.

Exposure of $\mathrm{CH}_{3} \mathrm{CN}_{0} @ \mathrm{CF}_{0.5}$ to white beam for $200 \mathrm{~s}$ causes an increase and broadening of $\pi^{*}$ resonance and a significant decrease in the intensity of $C_{1}$ and $C_{2}$ peaks of the $C$ K-edge spectrum (Figure 3a). To describe this spectral profile, the spectra of CF-0, C-ch, $\mathrm{C}$-ar, and central atom in the graphene model (Figure S1) are taken in a ratio of 1:1:2:2. The F K-edge spectrum of the irradiated $\mathrm{CH}_{3} \mathrm{CN}_{0} \mathrm{CF}_{0.5}$ shows mainly a decrease in the intensity of $\mathrm{F}_{2}$ peak (Figure $3 \mathrm{~b}$ ) and only isolated fluorine atoms from $\mathrm{CF}-0$ groups are needed to simulate the experimental profile. These results indicate that long-term irradiation of the fluorinated graphitic layers leads to their strong defluorination. The remaining fluorine atoms are separated from each other. A significant removal of fluorine occurs after the first 20-s irradiation and it is more pronounced for the $\mathrm{CH}_{3} \mathrm{CN}_{0} \mathrm{CF}_{0.3}$ sample (Figure 2).

\subsection{Electronic State of Nitrogen}

Electronic state of nitrogen from acetonitrile molecules embedded between the fluorinated graphitic layers is revealed using XPS N 1s and NEXAFS N K-edge spectra. The XPS N 1s spectrum of initial $\mathrm{CH}_{3} \mathrm{CN} @ \mathrm{CF}_{0.5}$ exhibits a single symmetrical peak at $\sim 399 \mathrm{eV}$ (Figure 4a). The white beam illumination of the sample for $80 \mathrm{~s}$ causes the appearance of two new components located at $\sim 398.1$ and $\sim 400.5 \mathrm{eV}$ and assigned to pyridinic $\mathrm{N}$ and $-\mathrm{NH}$ - species in carbon rings (pyrrolic $\mathrm{N}$ ), respectively [52]. The fraction of the pyrrolic $\mathrm{N}$ increases with the irradiation duration. This result indicates that $\mathrm{CH}_{3} \mathrm{CN}$ molecules are decomposed under photon-beam treatment and the released nitrogen and hydrogen atoms are incorporated into the surrounding $\mathrm{CF}_{\mathrm{x}}$ layers. Insertion of nitrogen into fluorinated graphitic layers was early observed for similar $\mathrm{CH}_{3} \mathrm{CN} @ \mathrm{CF}_{\mathrm{x}}$ samples heated at $250{ }^{\circ} \mathrm{C}$ in a vacuum [53].

NEXAFS measurements were performed to examine the initial stages of sample irradiation in more details, thus Figure $4 \mathrm{~b}$ compares N K-edge spectra of starting $\mathrm{CH}_{3} \mathrm{CN}_{\mathrm{N}} \mathrm{CF}_{0.5}$ and that after exposure to white beam during 2, 5, 20,80, and $200 \mathrm{~s}$. The irradiation of $\mathrm{CH}_{3} \mathrm{CN}_{0} @ \mathrm{CF}_{0.5}$ for $2 \mathrm{~s}$ already results in degradation of acetonitrile. The pre-edge peak $\mathrm{C} \equiv \mathrm{N}$ located in the initial spectrum at $\sim 399.9 \mathrm{eV}$ shifts by $0.3 \mathrm{eV}$ to the low-energy region, its intensity decreases, and new peak around $401.0 \mathrm{eV}$ appears. Our DFT calculations show the shift of the $\mathrm{C} \equiv \mathrm{N}$ peak can be attributed to the formation of HCN (Figure S3, Supporting Information). The peak at about $401.0 \mathrm{eV}$ corresponds to pyrrolic $\mathrm{N}$ species [54] and $\mathrm{N}_{2}$ molecules [55]. The intensity of this peak strongly reduces in the $\mathrm{N}$ K-edge spectrum of $\mathrm{CH}_{3} \mathrm{CN} @ \mathrm{CF}_{0.5}$ (Figure $4 \mathrm{~b}$ ) and $\mathrm{CH}_{3} \mathrm{CN}_{\mathrm{C}} \mathrm{CF}_{0.3}$ (Figure S3, Supporting Information) irradiated for $20 \mathrm{~s}$. 

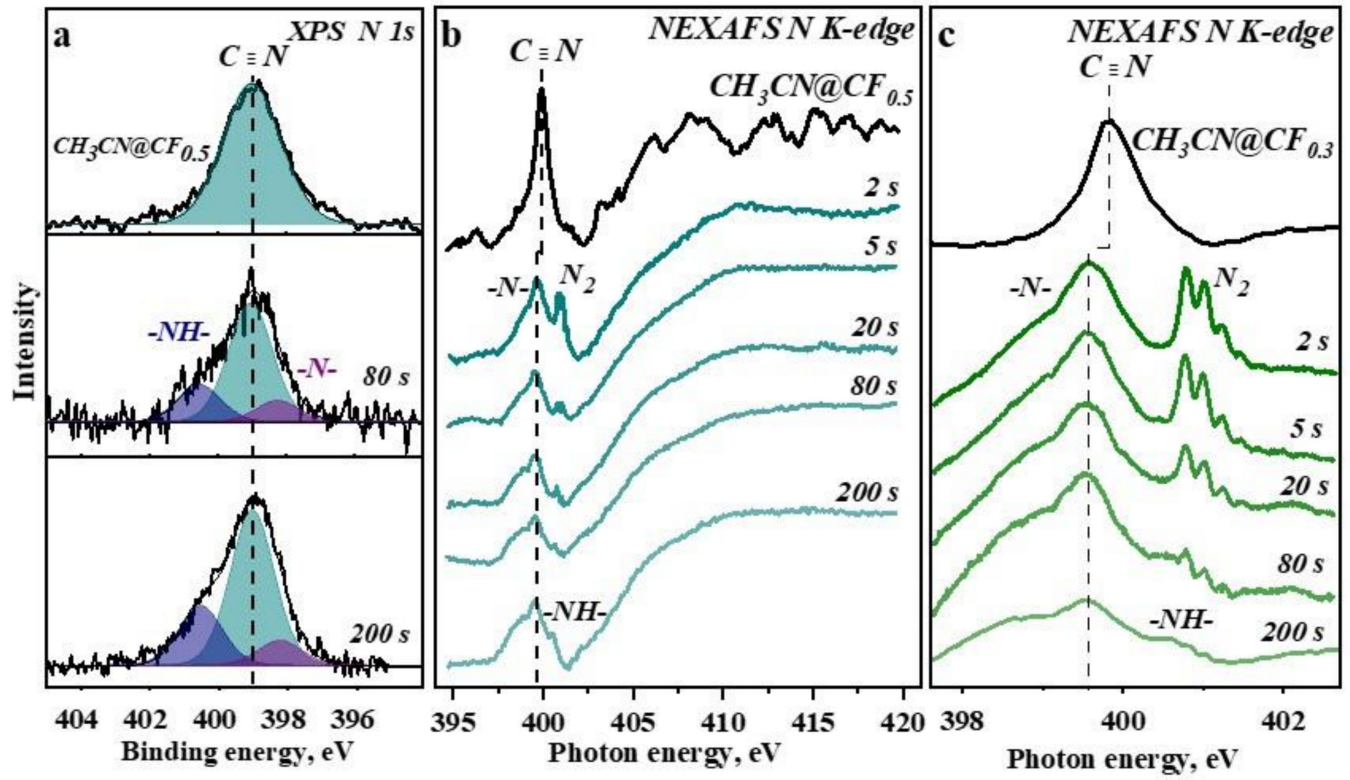

Figure 4. XPS N 1s spectra of initial $\mathrm{CH}_{3} \mathrm{CN}_{0} @ \mathrm{CF}_{0.5}$ and that irradiated for $80 \mathrm{~s}$ and $200 \mathrm{~s}(\mathbf{a})$. NEXAFS $\mathrm{N} \mathrm{K}$-spectra of $\mathrm{CH}_{3} \mathrm{CN} @ \mathrm{CF}_{0.5}(\mathbf{b})$ and $\mathrm{CH}_{3} \mathrm{CN}_{0} @ \mathrm{CF}_{0.3}$ (c) before and after white beam irradiation for $2 \mathrm{~s}, 5 \mathrm{~s}, 20 \mathrm{~s}, 80 \mathrm{~s}$, and $200 \mathrm{~s}$.

NEXAFS N K-edge spectra of starting and irradiated $\mathrm{CH}_{3} \mathrm{CN} @ \mathrm{CF}_{0.3}$ sample measured in a range of 397.5-403.0 eV are shown with a purpose to study the pre-edge peaks in detail (Figure 4c). The resonance emerging around $401.0 \mathrm{eV}$ is resolved into five peaks characteristic of vibrations of $\mathrm{N}_{2}$ molecules [56]. This proves the formation of $\mathrm{N}_{2}$ molecules as a result of the photolysis of $\mathrm{CH}_{3} \mathrm{CN}$ and the retention of these molecules between the fluorinated graphitic layers. The content of the trapped $\mathrm{N}_{2}$ molecules decreases with continuing irradiation and the molecules are not detected after 80-s irradiation. The peak at $\sim 400.6 \mathrm{eV}$ (Figure $4 \mathrm{~b}, \mathrm{c}$ ) corresponding to pyrrolic $\mathrm{N}$ at the boundaries of vacancies in $\mathrm{CF}_{\mathrm{x}}$ layers is identified according to the DFT calculations (Figure S3, Supporting Information). Incorporation of pyridinic $\mathrm{N}$ occurs at the first stages of samples irradiation and raises the shoulder at $398.8 \mathrm{eV}$ in the N K-edge spectra (Figure $4 \mathrm{~b}, \mathrm{c}$ ).

Mass spectrum of ion species measured upon the irradiation of $\mathrm{CH}_{3} \mathrm{CN}_{0} @ \mathrm{CF}_{0.3}$ sample is presented in Figure 5. The background ion peaks from residual air and molecular ion peaks are highlighted in black and red, respectively. The signal of $\mathrm{CO}_{2}{ }^{+}$ions $(\mathrm{m} / z=44)$ arising from the sample surface is taken as $\sim 100 \%$. Note that the amplitude of background $\mathrm{H}^{+}$and $\mathrm{H}_{2} \mathrm{O}^{+}$ions is an order of magnitude larger than this signal. The spectrum detects the ions being the decomposition products of $\mathrm{CH}_{3} \mathrm{CN}$ molecules. They are $\mathrm{CH}_{3}{ }^{+} / \mathrm{NH}^{+}$ $(m / z=15), \mathrm{C}_{2} \mathrm{H}_{2}{ }^{+} / \mathrm{CN}^{+}(m / z=26), \mathrm{C}_{2} \mathrm{H}_{3}{ }^{+} / \mathrm{CHN}^{+}(m / z=27), \mathrm{N}_{2}{ }^{+}(m / z=28), \mathrm{CH}_{2} \mathrm{~N}^{+}$ $(m / z=28), \mathrm{CH}_{2} \mathrm{CN}^{+}(m / z=40), \mathrm{CH}_{3} \mathrm{CN}^{+}(m / z=41)$, and $\mathrm{C}_{2} \mathrm{~N}_{2}{ }^{+}(m / z=52)$. The ions $\mathrm{FCNH}^{+}$ $(m / z=47) \mathrm{CF}^{+}(m / z=50)$, and $\mathrm{CF}_{3}{ }^{+}(\mathrm{m} / z=69)$ contain the atoms from fluorinated graphitic layers. A combination of fluorine with carbon may indicate that fluorine is removed along with the lattice carbon. 


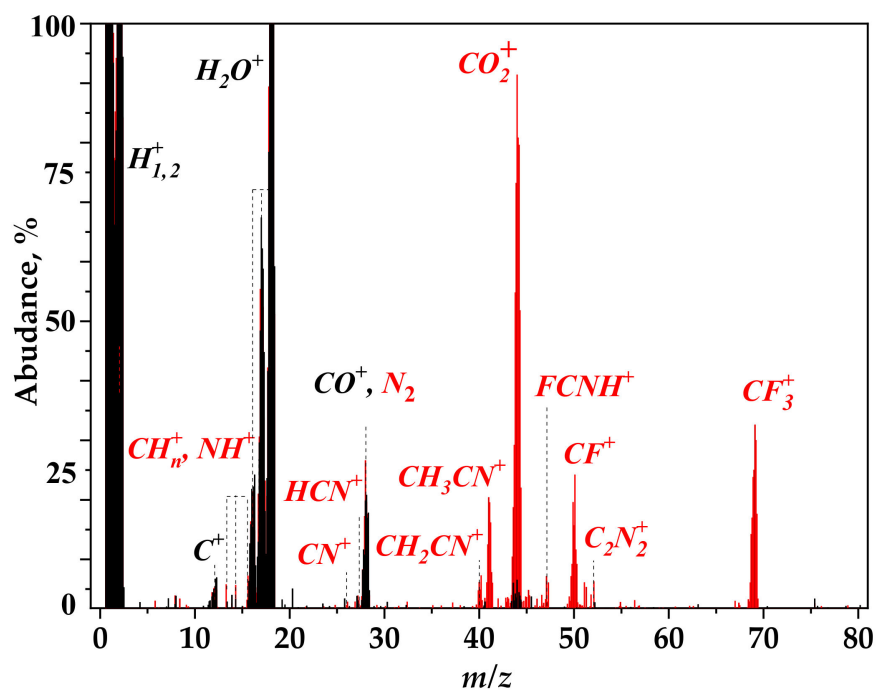

Figure 5. Mass spectrum registered upon white beam irradiation of $\mathrm{CH}_{3} \mathrm{CN}_{0} \mathrm{CF}_{0.3}$ sample.

\section{Discussion}

Fluorinated graphites of the composition $\mathrm{CF}_{0.5}$ and $\mathrm{CF}_{0.3}$ are insulators, and their XPS spectra are measured in a laboratory spectrometer where charging of sample under $\mathrm{X}$-ray photon exposure is compensated. Analysis of XPS data indicates that $\mathrm{C}-\mathrm{F}$ bonds are covalent and they are weaker in $\mathrm{CF}_{0.3}$ layers. These layers also contain larger fractions of aromatic areas and bare carbon atoms located nearby $\mathrm{CF}$ groups as compared to $\mathrm{CF}_{0.5}$ layers. The DFT modeling of NEXAFS C K- and F K-edge spectra of initial $\mathrm{CF}_{0.5}$ reveals that fluorine atoms in the layers preferably form CF chains, alternating with polyene-like carbon chains. The $\mathrm{CF}$ chains are shorter in $\mathrm{CF}_{0.3}$ layers.

NEXAFS C K- and F K-edge spectra of both studied samples exhibit a large decrease in the intensity of the peaks corresponding to the $\mathrm{C}-\mathrm{F}$ bonds already after polychromatic photon beam exposure for $20 \mathrm{~s}$ (Figure 2). A probing depth of the spectra acquired in the TEY mode is a few nanometers [38], thus, we estimate that at least ten upper layers lose fluorine. The areas of C-F components in XPS C 1s spectra of both samples decrease by about 2.4 times after irradiation for $200 \mathrm{~s}$ (Table S1, Supporting Information). The shape of the $\mathrm{F}$ K-edge spectrum of the irradiated $\mathrm{CF}_{0.5}$ well corresponds to the electronic state of fluorine in isolated CF groups, i.e., not adjacent to other CF groups (Figure 3b).

A part of fluorine atoms removed from basal graphitic planes is attached to their edges as $\mathrm{CF}_{2}$ and $\mathrm{CF}_{3}$ groups and amounts of these groups are markedly larger for $\mathrm{CF}_{0.5}$ layers (Figure 1a,b). The formation of these groups means that a fluorine atom may leave a fluorinated graphitic layer together with the carbon neighbor. The $\mathrm{CF}^{+}$and $\mathrm{CF}_{3}{ }^{+}$ion signals detected in the mass spectrum upon the irradiation of $\mathrm{CH}_{3} \mathrm{CN} @ \mathrm{CF}_{0.3}$ sample (Figure 5) confirm this. According to our DFT calculations, fluorine atoms located in the center of CF chains have larger binding energies than fluorine atoms at the chain edges (Table S2, Figure S4, Supporting Information). Therefore, the C-F bonds in long CF chains that are present in $\mathrm{CF}_{0.5}$ layers are stronger than bonds between bare carbon atoms and fluorinated ones $(\mathrm{C}-\mathrm{CF})$. The latter $\mathrm{C}-\mathrm{CF}$ bonds break more easily, producing vacancies in the carbon network. The edge $\mathrm{C}-\mathrm{F}$ bonds, which are predominant in short $\mathrm{CF}$ chains of $\mathrm{CF}_{0.3}$ layers, dissociate under the radiation and this explains the less efficient destruction of $\mathrm{C}-\mathrm{C}$ bonds observed for this sample.

NMR study of fluorinated graphites with embedded acetonitrile molecules revealed that interactions between the guests and matrices have van-der-Waals character [57]. Such weak interactions should not influence the radiation stability of the constituents. According to NEXAFS N K-edge spectra the $\mathrm{CH}_{3} \mathrm{CN}$ molecules located between fluorinated graphene layers dissociate under irradiation for $2 \mathrm{~s}$ (Figure $4 \mathrm{~b}, \mathrm{c}$ ). The features detected in the spectra measured at various stages of the irradiation are assigned to $\mathrm{HCN}$ and $\mathrm{N}_{2}$ molecules, and 
pyridinic and pyrrolic nitrogen atoms at vacancies edges of $\mathrm{CF}_{\mathrm{x}}$ layers. The fractions of these nitrogen forms are determined from the decomposition of N K-edge spectra (Figure S5, Supporting Information).

The evolution of nitrogen forms in $\mathrm{CH}_{3} \mathrm{CN}_{\mathrm{N}} \mathrm{CF}_{0.5}$ and $\mathrm{CH}_{3} \mathrm{CN} @ \mathrm{CF}_{0.3}$ with the exposure time is illustrated in Figure $6 \mathrm{a}, \mathrm{b}$. The main product of the $\mathrm{CH}_{3} \mathrm{CN}$ photolysis is $\mathrm{HCN}$ molecules. Their preferable formation according to the path $\mathrm{CH}_{3} \mathrm{CN} \rightarrow \mathrm{CH}+\mathrm{H}+\mathrm{HCN}$ was previously observed under the action of UV light [23], electron beam [20], and photon beam [22]. The HCN concentration after the first stage of the irradiation for $2 \mathrm{~s}$ is $\sim 64 \%$ for $\mathrm{CH}_{3} \mathrm{CN} @ \mathrm{CF}_{0.5}$ and $~ 57 \%$ for $\mathrm{CH}_{3} \mathrm{CN} @ \mathrm{CF}_{0.3}$, and it reduces to $\sim 49 \%$ for $\mathrm{CH}_{3} \mathrm{CN} @ \mathrm{CF}_{0.5}$ and $\sim 47 \%$ for $\mathrm{CH}_{3} \mathrm{CN} @ \mathrm{CF}_{0.3}$ after the 200-s exposure. Since the pyrrolic $\mathrm{N}$ is detected in the NEXAFS N K-edge spectra measured for the samples after the 80-s exposure, we suppose that decomposition of $\mathrm{HCN}$ with prolonged irradiation of samples contributes to the formation of this kind of nitrogen species.
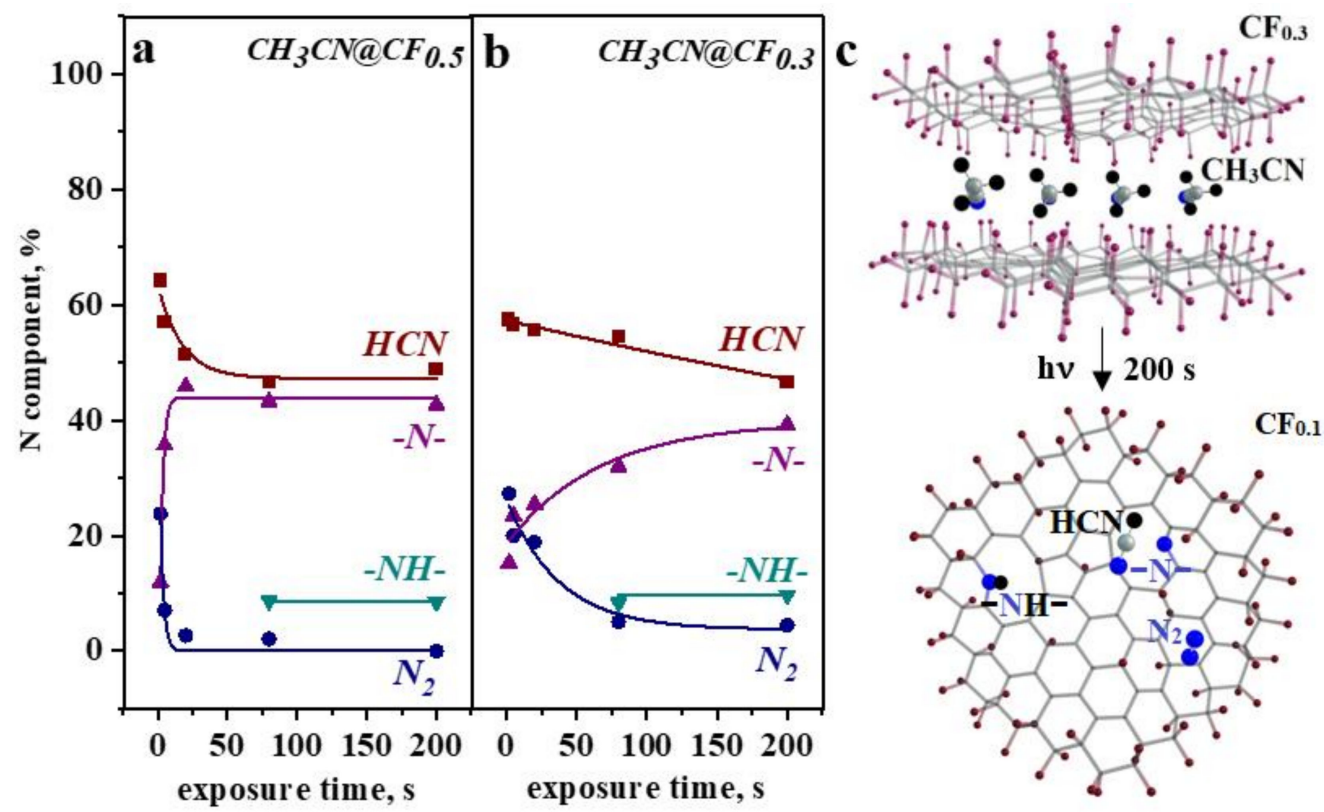

Figure 6. Dependence of the NEXAFS N K-edge components from $\mathrm{HCN}, \mathrm{N}_{2}$, pyridinic $\mathrm{N}$, and pyrrolic $\mathrm{N}$ on the time of exposure of $\mathrm{CH}_{3} \mathrm{CN} @ \mathrm{CF}_{0.5}(\mathbf{a})$ and $\mathrm{CH}_{3} \mathrm{CN} @ \mathrm{CF}_{0.3}$ (b) to white beam light. The model of evolution of $\mathrm{CH}_{3} \mathrm{CN}_{0} \mathrm{CF}_{0.3}$ structure and composition under the irradiation (c).

The initial photolysis of $\mathrm{CH}_{3} \mathrm{CN}$ molecules yields also $\mathrm{N}_{2}$ molecules and pyridinic $\mathrm{N}$ atoms (Figure 6a,b). A weak signal of nitrogen ions was observed when gaseous $\mathrm{CH}_{3} \mathrm{CN}$ was photoionized by the monochromatic SR beam with a photon energy of $42 \mathrm{eV}$ [20]. The $\mathrm{CF}_{\mathrm{x}}$ matrix probably facilitates the abstraction of the nitrogen atoms from acetonitrile molecules in our case. Mass spectrum of photo-induced ions detects the $\mathrm{N}_{2}{ }^{+}$signal (Figure 5). The $\mathrm{N}_{2}$ molecule fraction is twice the fraction of pyridinic $\mathrm{N}$ developed in $\mathrm{CF}_{\mathrm{X}}$ layers. However, with an increase in the exposure time, $\mathrm{N}_{2}$ content decreases, which is accompanied by a growth of the content of pyridinic $\mathrm{N}$. This behavior indicates photodissociation of $\mathrm{N}_{2}$ and incorporation of the produced nitrogen atoms in the surrounding defective $\mathrm{CF}_{\mathrm{x}}$ layers. The process is faster for the $\mathrm{CH}_{3} \mathrm{CN} @ \mathrm{CF}_{0.5}$ sample. The reason may be a larger amount of atomic vacancies in the layers as the XPS C 1s and F 1s spectra of the sample detect (Figure 1).

Figure $6 c$ schematically presents changes that occurred for fluorinated graphene layers with acetonitrile guests under the influence of non-monochromatized SR light. The matrix layers lose a part of fluorine and acquire nitrogen atoms. These atoms are located at the boundaries of vacancies, produced when fluorine atoms are removed from the layer together with carbon. The photolysis of acetonitrile produces $\mathrm{N}_{2}$ and HCN molecules. DFT calculations show that these molecules are readily adsorbed on the nitrogen-doped $\mathrm{CF}_{\mathrm{X}}$ 
layer. Pyridinic $\mathrm{N}$ atoms and $\mathrm{CF}$ groups create the preferred positions for $\mathrm{HCN}$ and $\mathrm{N}_{2}$ molecules, respectively.

\section{Conclusions}

Fluorinated graphites with the composition of the layers $\mathrm{CF}_{0.3}$ and $\mathrm{CF}_{0.5}$ were synthesized using a fluorinating agent $\mathrm{BrF}_{3}$ at room temperature. DFT modeling of NEXAFS $\mathrm{C}$ K-edge and $\mathrm{F} \mathrm{K}$-edge spectra showed that fluorine atoms form the fluorinated carbon chains alternating with polyene-like carbon chains in $\mathrm{CF}_{0.5}$ layers. These chains were shorter in the $\mathrm{CF}_{0.3}$ layers, where the $\mathrm{CF}$ groups have two bare carbon neighbors on average. The interlayer space of the fluorinated graphites was filled by $\mathrm{CH}_{3} \mathrm{CN}$. Photolysis

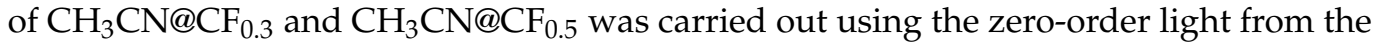
Russian-German dipole Beamline of the synchrotron source BESSY II. The photon irradiation led to a partial defluorination of the layers and the formation of vacancy defects. The XPS C 1s and F 1s spectra showed that the amount of vacancies is larger in the layers with an initial composition of $\mathrm{CF}_{0.5}$. $\mathrm{C}-\mathrm{F}$ bonds in these layers were stronger than the bonds between the fluorinated carbon and bare carbon neighbor that caused the preferred breakage of the latter bonds. $\mathrm{CH}_{3} \mathrm{CN}$ molecules were completely decomposed during the first two seconds of the SR zero-order light exposure. The main products were $\mathrm{HCN}$ and $\mathrm{N}_{2}$ molecules and pyridinic $\mathrm{N}$ atoms, introduced into the $\mathrm{CF}_{\mathrm{x}}$ layers at the vacancy boundaries. Upon further irradiation, $\mathrm{N}_{2}$ molecules dissociated and the released nitrogen atoms gave mainly pyridinic $\mathrm{N}$ defects in the fluorinated graphene layers. This dissociation was faster in the $\mathrm{CF}_{0.5}$ layers. The products of $\mathrm{HCN}$ photolysis contributed to the formation of pyrrolic $\mathrm{N}$ species. The study shows that the products of the photolysis of $\mathrm{CH}_{3} \mathrm{CN}$ depend on the time of irradiation and the fluorine loading of the fluorographitic matrix. Our results can be crucial when using $\mathrm{CH}_{3} \mathrm{CN}_{\mathrm{C}} \mathrm{CF}_{\mathrm{x}}$ systems in environments with intense light from UV to soft X-rays.

Supplementary Materials: The following supporting information can be downloaded at: https: //www.mdpi.com/article/10.3390/nano12020231/s1. Figure S1. Experimental and theoretical NEXAFS C K-edge spectra of graphite and F K-edge spectra of $(\mathrm{CF})_{n}$. Table S1. The fitting data of the XPS C1s spectra. Figure S2. Unoccupied molecular orbitals responsible for main features in $\mathrm{F}$ K-edge spectra. Figure S3. Experimental NEXAFS N K-edge spectra of $\mathrm{CH}_{3} \mathrm{CN}_{0} \mathrm{CF}_{0.3}$ before and after irradiation. Figure S4. Optimized fluorinated graphene fragments. Table S2. Binding energies of fluorine atoms. Figure S5. Experimental NEXAFS N K-edge spectra of $\mathrm{CH}_{3} \mathrm{CN}_{0} @ \mathrm{CF}_{0.5}$ in comparison with the spectra calculated for $\mathrm{CH}_{3} \mathrm{CN}, \mathrm{HCN}$ and nitrogen species in a fluorinated graphene layer. References $[58,59]$ are cited in the supplementary materials.

Author Contributions: Conceptualization, A.V.O. and L.G.B.; material preparation, D.V.P. and G.N.C.; measurements, I.P.A., A.A.M. and D.A.S.; methodology and writing-original draft preparation, G.I.S. and Y.V.F.; writing — review and editing, L.G.B. All authors have read and agreed to the published version of the manuscript.

Funding: The work was funded by the Russian Foundation for Basic Research (Grant No. 1829-19073) and the Ministry of Science and Higher Education of the Russian Federation, (project No. 121031700314-5). A.A.M. and D.A.S. acknowledge BMBF (grant no. 05K19KER and 0519ODR, respectively).

Institutional Review Board Statement: Not applicable.

Acknowledgments: The authors thank the Helmholtz-Zentrum Berlin für Materialien und Energie for allocation of beamtime and support within bilateral program "Russian-German Laboratory at BESSY II".

Conflicts of Interest: The authors declare no conflict of interest. The funders had no role in the design of the study; in the collection, analyses, or interpretation of data and their representation in the manuscript. 


\section{References}

1. Dubois, M.; Guérin, K.; Hamwi, A.; Vinogradov, A. Nature of C-F Bonds in Fluorinated Carbons. In New Fluorinated Carbons: Fundamentals and Applications; Boltalina, O.V., Nakajima, T., Eds.; Elsevier: Amsterdam, The Netherlands, 2017 ; pp. $215-243$.

2. Nakajima, T. (Ed.) Fluorine-Carbon and Fluoride-Carbon Materials; CRC Press: Boca Raton, FL, USA, 1994 ; ISBN 9780429180811.

3. Yoshida, K.; Sugawara, Y.; Saitoh, M.; Matsumoto, K.; Hagiwara, R.; Matsuo, Y.; Kuwabara, A.; Ukyo, Y.; Ikuhara, Y. Microscopic characterization of the C-F bonds in fluorine-graphite intercalation compounds. J. Power Sources 2020, 445, 227320. [CrossRef]

4. Panich, A.M. Nuclear magnetic resonance study of fluorine-graphite intercalation compounds and graphite fluorides. Synth. Met. 1999, 100, 169-185. [CrossRef]

5. Paasonen, V.M.; Nazarov, A.S. Thermal stability of graphite fluoride intercalation compounds. Inorg. Mater. 2001, 37, 452-455. [CrossRef]

6. Makotchenko, V.G.; Nazarov, A.S.; Yakovlev, I.I. Dicarbon fluoride interclation compounds as new moleculea containers of volitale compounds. Dokl. Chem. 2001, 380, 252-254. [CrossRef]

7. Makarova, T.L.; Zagaynova, V.S.; Inan, G.; Okotrub, A.V.; Chekhova, G.N.; Pinakov, D.V.; Bulusheva, L.G. Structural Evolution and Magnetic Properties of Underfluorinated $C_{2}$ F. J. Supercond. Nov. Magn. 2012, 25, 79-83. [CrossRef]

8. Makarova, T.L.; Shelankov, A.L.; Shames, A.I.; Zyrianova, A.A.; Komlev, A.A.; Chekhova, G.N.; Pinakov, D.V.; Bulusheva, L.G.; Okotrub, A.V.; Lähderanta, E. Tabby graphene: Dimensional magnetic crossover in fluorinated graphite. Sci. Rep. 2017, 7, 16544. [CrossRef]

9. Sysoev, V.I.; Bulavskiy, M.O.; Pinakov, D.V.; Chekhova, G.N.; Asanov, I.P.; Gevko, P.N.; Bulusheva, L.G.; Okotrub, A.V. Chemiresistive properties of imprinted fluorinated graphene films. Materials 2020, 13, 3538. [CrossRef] [PubMed]

10. Pinakov, D.V.; Chekhova, G.N.; Okotrub, A.V.; Asanov, I.P.; Shubin, Y.V.; Fedorovskaya, E.O.; Plyusnin, P.E.; Bulusheva, L.G. Structure and supercapacitor properties of few-layer low-fluorinated graphene materials. J. Mater. Sci. 2018, 53, 13053-13066. [CrossRef]

11. Makotchenko, V.G.; Grayfer, E.D.; Mikheev, A.N.; Arzhannikov, A.V.; Saprykin, A.I. Microwave exfoliation of organic-intercalated fluorogaphites. Chem. Commun. 2020, 56, 1895-1898. [CrossRef]

12. Okotrub, A.V.; Fedorovskaya, E.O.; Senkovskiy, B.V.; Bulusheva, L.G. Nitrogen species in few-layer graphene produced by thermal exfoliation of fluorinated graphite intercalation compounds. Phys. Status Solidi B 2015, 252, 2444-2450. [CrossRef]

13. Asanov, I.P.; Bulusheva, L.G.; Dubois, M.; Yudanov, N.F.; Alexeev, A.V.; Makarova, T.L.; Okotrub, A.V. Graphene nanochains and nanoislands in the layers of room-temperature fluorinated graphite. Carbon 2013, 59, 518-529. [CrossRef]

14. Lee, J.H.; Koon, G.K.W.; Shin, D.W.; Fedorov, V.E.; Choi, J.-Y.; Yoo, J.-B.; Özyilmaz, B. Property control of graphene by employing "semi-ionic" liquid fluorination. Adv. Funct. Mater. 2013, 23, 3329-3334. [CrossRef]

15. Pinakov, D.V.; Makotchenko, V.G.; Semushkina, G.I.; Chekhova, G.N.; Prosvirin, I.P.; Asanov, I.P.; Fedoseeva, Y.V.; Makarova, A.A.; Shubin, Y.V.; Okotrub, A.V.; et al. Redox reactions between acetonitrile and nitrogen dioxide in the interlayer space of fluorinated graphite matrices. Phys. Chem. Chem. Phys. 2021, 23, 10580-10590. [CrossRef]

16. Karlický, F.; Otyepka, M. Band gaps and optical spectra from single- and double-layer fluorographene to graphite fluoride: Many-body effects and excitonic states. Ann. Phys. 2014, 526, 408-414. [CrossRef]

17. Gong, P.; Wang, J.; Sun, W.; Wu, D.; Wang, Z.; Fan, Z.; Wang, H.; Han, X.; Yang, S. Tunable photoluminescence and spectrum split from fluorinated to hydroxylated graphene. Nanoscale 2014, 6, 3316-3324. [CrossRef]

18. Pinakov, D.V.; Logvinenko, V.A. The relationship between properties of fluorinated graphite intercalates and matrix composition. J. Therm. Anal. Calorim. 2006, 86, 173-178. [CrossRef]

19. Chekhova, G.N.; Pinakov, D.V.; Shubin, Y.V.; Fadeeva, V.P.; Tikhova, V.D.; Okotrub, A.V.; Bulusheva, L.G. Room temperature synthesis of fluorinated graphite intercalation compounds with low fluorine loading of host matrix. J. Fluor. Chem. 2020, 232, 109482. [CrossRef]

20. Parkes, M.A.; Douglas, K.M.; Price, S.D. Ionization of acetonitrile. Int. J. Mass Spectrom. 2019, 438, 97-106. [CrossRef]

21. De Ribero, F.A.; Almeida, G.C.; Garcia-Basabe, Y.; Wolff, W.; Boechat-Roberty, H.M.; Rocco, M.L.M. Non-thermal ion desorption from an acetonitrile $\left(\mathrm{CH}_{3} \mathrm{CN}\right)$ astrophysical ice analogue studied by electron stimulated ion desorption. Phys. Chem. Chem. Phys. 2015, 17, 27473-27480. [CrossRef]

22. Schwell, M.; Jochims, H.-W.; Baumgärtel, H.; Leach, S. VUV photophysics of acetonitrile: Fragmentation, fluorescence and ionization in the 7-22 eV region. Chem. Phys. 2008, 344, 164-175. [CrossRef]

23. Bulak, M.; Paardekooper, D.M.; Fedoseev, G.; Linnartz, H. Photolysis of acetonitrile in a water-rich ice as a source of complex organic molecules: $\mathrm{CH}_{3} \mathrm{CN}$ and $\mathrm{H}_{2} \mathrm{O}: \mathrm{CH}_{3} \mathrm{CN}$ ices. Astron. Astrophys. 2021, 647, A82. [CrossRef]

24. Men, S.; Anderson, A.J.; Mayanovic, R.A. In situ Monitoring of Synchrotron X-Ray-Induced Radiolysis Effects on Chromium Species Using X-Ray Absorption Spectroscopy. J. Appl. Spectrosc. 2017, 84, 342-345. [CrossRef]

25. Yang, Y.-C.; Wang, C.-H.; Hwu, Y.-K.; Je, J.-H. Synchrotron X-ray synthesis of colloidal gold particles for drug delivery. Mater. Chem. Phys. 2006, 100, 72-76. [CrossRef]

26. Kaito, C.; Kimura, Y.; Hanamoto, K.; Sasaki, M.; Kimura, S.; Nakada, T.; Saito, Y.; Koike, C.; Nakayama, Y. Carbyne formation be synchrotron radiation. Nuclear Instrum. Methods Phys. Res. A 2001, 467-468, 1217-1220. [CrossRef]

27. Sedelnikova, O.; Gurova, O.; Makarova, A.; Fedorenko, A.; Nikolenko, A.; Plyusnin, P.; Arenal, R.; Bulusheva, L.; Okotrub, A. Light-Induced Sulfur Transport inside Single-Walled Carbon Nanotubes. Nanomaterials 2020, 10, 818. [CrossRef] 
28. Prezioso, S.; Perrozzi, F.; Donarelli, M.; Stagnini, E.; Treossi, E.; Palermo, V.; Santucci, S.; Nardone, M.; Moras, P.; Ottaviano, L. Dose and wavelength dependent study of graphene oxide photoreduction with VUV Synchrotron radiation. Carbon 2014, 79, 478-485. [CrossRef]

29. Becke, A.D. Density-functional thermochemistry. III. The role of exact exchange. J. Chem. Phys. 1993, 98, 5648-5652. [CrossRef]

30. Lee, C.; Yang, W.; Parr, R.G. Development of the Colle-Salvetti correlation-energy formula into a functional of the electron density. Phys. Rev. B 1988, 37, 785-789. [CrossRef]

31. Leenaerts, O.; Peelaers, H.; Hernández-Nieves, A.D.; Partoens, B.; Peeters, F.M. First-principles investigation of graphene fluoride and graphane. Phys. Rev. B 2010, 82, 195436. [CrossRef]

32. Makarova, T.L.; Shelankov, A.L.; Zyrianova, A.A.; Veinger, A.I.; Tisnek, T.V.; Lähderanta, E.; Shames, A.I.; Okotrub, A.V.; Bulusheva, L.G.; Chekhova, G.N.; et al. Edge state magnetism in zigzag-interfaced graphene via spin susceptibility measurements. Sci. Rep. 2015, 5, 13382. [CrossRef]

33. Bulusheva, L.G.; Okotrub, A.V.; Shnitov, V.V.; Bryzgalov, V.V.; Boltalina, O.V.; Gol'dt, I.V.; Vyalikh, D.V. Electronic structure of $\mathrm{C}_{60} \mathrm{~F}_{36}$ studied by quantum-chemical modeling of experimental photoemission and x-ray absorption spectra. J. Chem. Phys. 2009, 130, 014704. [CrossRef]

34. Poe, B.; Seifert, F.; Sharp, T.; Wu, Z. ELNES spectroscopy of mixed Si coordination minerals. Phys. Chem. Miner. 1997, 24, 477-487. [CrossRef]

35. Okotrub, A.V.; Asanov, I.P.; Yudanov, N.F.; Babin, K.S.; Gusel'nikov, A.V.; Nedoseikina, T.I.; Gevko, P.N.; Bulusheva, L.G.; Osváth, Z.; Biró, L.P. Development of graphene layers by reduction of graphite fluoride $\mathrm{C}_{2}$ F surface. Phys. Status Solidi B 2009, 246, 2545-2548. [CrossRef]

36. Aseeva, E.A.; Pinakov, D.V.; Oglezneva, I.M.; Chekhova, G.N.; Mazalov, L.N.; Shubin, Y.V. X-ray photoelectron spectroscopy study of intercalated compounds of fluorinated graphite $\mathrm{C}_{2} \mathrm{~F}_{x} \mathrm{Br}_{0.01} \cdot \mathrm{yCH}_{3} \mathrm{CN}$. J. Struct. Chem. 2006, 47, 930-938. [CrossRef]

37. Tressaud, A.; Moguet, F.; Flandrois, S.; Chambon, M.; Guimon, C.; Nanse, G.; Papirer, E.; Gupta, V.; Bahl, O.P. On the nature of C-F bonds in various fluorinated carbon materials: XPS and TEM investigations. J. Phys. Chem. Solids 1996, 57, 745-751. [CrossRef]

38. Lavskaya, Y.V.; Bulusheva, L.G.; Okotrub, A.V.; Yudanov, N.F.; Vyalikh, D.V.; Fonseca, A. Comparative study of fluorinated single- and few-wall carbon nanotubes by X-ray photoelectron and X-ray absorption spectroscopy. Carbon 2009, 47, 1629-1636. [CrossRef]

39. Bittencourt, C.; Van Lier, G.; Ke, X.; Suarez-Martinez, I.; Felten, A.; Ghijsen, J.; Van Tendeloo, G.; Ewels, C.P. Spectroscopy and defect identification for fluorinated carbon nanotubes. ChemPhysChem 2009, 10, 920-925. [CrossRef]

40. Okotrub, A.V.; Yudanov, N.F.; Asanov, I.P.; Vyalikh, D.V.; Bulusheva, L.G. Anisotropy of chemical bonding in semifluorinated graphite $\mathrm{C}_{2} \mathrm{~F}$ revealed with angle-resolved X-ray absorption spectroscopy. ACS Nano 2013, 7, 65-74. [CrossRef]

41. Bulusheva, L.G.; Okotrub, A.V. Electronic Structure of Fluorinated Graphene. In New Fluorinated Carbons: Fundamentals and Applications; Boltalina, O.V., Nakajima, T., Eds.; Elsevier: Amsterdam, The Netherlands, 2017; pp. 177-213.

42. Bakharev, P.V.; Huang, M.; Saxena, M.; Lee, S.W.; Joo, S.H.; Park, S.O.; Dong, J.; Camacho-Mojica, D.C.; Jin, S.; Kwon, Y.; et al. Chemically induced transformation of chemical vapour deposition grown bilayer graphene into fluorinated single-layer diamond. Nat. Nanotechnol. 2020, 15, 59-66. [CrossRef]

43. Herraiz, M.; Dubois, M.; Batisse, N.; Hajjar-Garreau, S.; Simon, L. Large-scale synthesis of fluorinated graphene by rapid thermal exfoliation of highly fluorinated graphite. Dalt. Trans. 2018, 47, 4596-4606. [CrossRef]

44. Zhou, S.; Sherpa, S.D.; Hess, D.W.; Bongiorno, A. Chemical bonding of partially fluorinated graphene. J. Phys. Chem. C 2014, 118, 26402-26408. [CrossRef]

45. Struzzi, C.; Scardamaglia, M.; Reckinger, N.; Sezen, H.; Amati, M.; Gregoratti, L.; Colomer, J.-F.; Ewels, C.; Snyders, R.; Bittencourt, C. Probing plasma fluorinated graphene via spectromicroscopy. Phys. Chem. Chem. Phys. 2017, 19, 31418-31428. [CrossRef]

46. Fischer, D.A.; Wentzcovitch, R.M.; Carr, R.G.; Continenza, A.; Freeman, A.J. Graphitic interlayer states: A carbon K near-edge X-ray-absorption fine-structure study. Phys. Rev. B 1991, 44, 1427-1429. [CrossRef] [PubMed]

47. Batson, P.E. Carbon $1 s$ near-edge-absorption fine structure in graphite. Phys. Rev. B 1993, 48, 2608-2610. [CrossRef]

48. Brühwiler, P.A.; Maxwell, A.J.; Puglia, C.; Nilsson, A.; Andersson, S.; Mårtensson, N. $\pi^{*}$ and $\sigma^{*}$ excitons in C 1 s absorption of graphite. Phys. Rev. Lett. 1995, 74, 614-617. [CrossRef] [PubMed]

49. Liang, X.; Pan, D.; Lao, M.; Liang, S.; Huang, D.; Zhou, W.; Guo, J. Structural evolution of fluorinated graphene upon molten-alkali treatment probed by X-ray absorption near-edge structure spectroscopy. Appl. Surf. Sci. 2017, 404, 1-6. [CrossRef]

50. Ahmad, Y.; Dubois, M.; Guérin, K.; Hamwi, A.; Fawal, Z.; Kharitonov, A.P.; Generalov, A.V.; Klyushin, A.Y.; Simonov, K.A.; Vinogradov, N.A.; et al. NMR and NEXAFS study of various graphite fluorides. J. Phys. Chem. C 2013, 117, 13564-13572. [CrossRef]

51. Bulusheva, L.G.; Okotrub, A.V.; Yudanov, N.F. Atomic arrangement and electronic structure of graphite fluoride $\mathrm{C}_{2} \mathrm{~F}$. Phys. Low-Dimensional Struct. 2002, 7, 1-14.

52. Kiuchi, H.; Kondo, T.; Sakurai, M.; Guo, D.; Nakamura, J.; Niwa, H.; Miyawaki, J.; Kawai, M.; Oshima, M.; Harada, Y. Characterization of nitrogen species incorporated into graphite using low energy nitrogen ion sputtering. Phys. Chem. Chem. Phys. 2016, 18, 458-465. [CrossRef] [PubMed] 
53. Fedoseeva, Y.V.; Okotrub, A.V.; Asanov, I.P.; Pinakov, D.V.; Chekhova, G.N.; Tur, V.A.; Plyusnin, P.E.; Vyalikh, D.V.; Bulusheva, L.G. Nitrogen inserting in fluorinated graphene via annealing of acetonitrile intercalated graphite fluoride. Phys. Status Solidi $B$ 2014, 251, 2530-2535. [CrossRef]

54. Leinweber, P.; Kruse, J.; Walley, F.L.; Gillespie, A.; Eckhardt, K.-U.; Blyth, R.I.R.; Regier, T. Nitrogen K -edge XANES-An overview of reference compounds used to identify 'unknown' organic nitrogen in environmental samples. J. Synchrotron Radiat. 2007, 14, 500-511. [CrossRef]

55. Bulusheva, L.G.; Okotrub, A.V.; Kudashov, A.G.; Shubin, Y.V.; Shlyakhova, E.V.; Yudanov, N.F.; Pazhetnov, E.M.; Boronin, A.I.; Vyalikh, D.V. Effect of Fe/Ni catalyst composition on nitrogen doping and field emission properties of carbon nanotubes. Carbon 2008, 46, 864-869. [CrossRef]

56. Gillespie, A.W.; Walley, F.L.; Farrell, R.E.; Regier, T.Z.; Blyth, R.I.R. Calibration method at the N K -edge using interstitial nitrogen gas in solid-state nitrogen-containing inorganic compounds. J. Synchrotron Radiat. 2008, 15, 532-534. [CrossRef] [PubMed]

57. Vyalikh, A.; Bulusheva, L.G.; Chekhova, G.N.; Pinakov, D.V.; Okotrub, A.V.; Scheler, U. Fluorine patterning in room-temperature fluorinated graphite determined by solid-state NMR and DFT. J. Phys. Chem. C 2013, 117, 7940-7948. [CrossRef]

58. ADF 2020.1. SCM, Theoretical Chemistry; Vrije Universiteit: Amsterdam, The Netherlands, 2020.

59. Hait, D.; Head-Gordon, M. Highly accurate prediction of core spectra of molecules at density functional theory cost: Attaining sub-electronvolt error from a restricted open-shell Kohn-Sham approach. J. Phys. Chem. Lett. 2020, 11, 775-786. [CrossRef] [PubMed] 